\title{
State of the Art
}

\section{Indoor Air Pollution and Asthma in Children}

\author{
Patrick N. Breysse ${ }^{1}$, Gregory B. Diette ${ }^{2}$, Elizabeth C. Matsui ${ }^{3}$, Arlene M. Butz ${ }^{3}$, Nadia N. Hansel ${ }^{2}$, \\ and Meredith C. McCormack ${ }^{2}$ \\ ${ }^{1}$ Department of Environmental Heath Sciences, Johns Hopkins University Bloomberg School of Public Health; ${ }^{2}$ Department of Medicine, and \\ ${ }^{3}$ Department of Pediatrics, Johns Hopkins University School of Medicine, Baltimore, Maryland
}

\begin{abstract}
The purpose of this article is to review indoor air pollution factors that can modify asthma severity, particularly in inner-city environments. While there is a large literature linking ambient air pollution and asthma morbidity, less is known about the impact of indoor air pollution on asthma. Concentrating on the indoor environments is particularly important for children, since they can spend as much as $90 \%$ of their time indoors. This review focuses on studies conducted by the Johns Hopkins Center for Childhood Asthma in the Urban Environment as well as other relevant epidemiologic studies. Analysis of exposure outcome relationships in the published literature demonstrates the importance of evaluating indoor home environmental air pollution sources as risk factors for asthma morbidity. Important indoor air pollution determinants of asthma morbidity in urban environments include particulate matter (particularly the coarse fraction), nitrogen dioxide, and airborne mouse allergen exposure. Avoidance of harmful environmental exposures is a key component of national and international guideline recommendations for management of asthma. This literature suggests that modifying the indoor environment to reduce particulate matter, $\mathrm{NO}_{2}$, and mouse allergen may be an important asthma management strategy. More research documenting effectiveness of interventions to reduce those exposures and improve asthma outcomes is needed.
\end{abstract}

Keywords: particulate matter; air pollution; pediatric; urban; bronchial hyperreactivity

According to the World Health Organization, 24\% of the global disease burden and $23 \%$ of all deaths are attributable to environmental factors (1). The causal pathway from exposure to disease and death is often complex and poorly understood. These risks are not evenly distributed across all age groups. Children may be particularly susceptible to the adverse environmental effects, as the proportion of deaths among children attributed to the environment is as high as $36 \%$ (1).

While there is a large literature linking ambient air pollution and cardiopulmonary disease (2-6), less is known about the impact of indoor air pollution on morbidity and mortality. Children, the elderly, and women are the most vulnerable with respect to potential indoor air pollution health effects because they spend more time in the home environment. Time activity studies have estimated that children and the elderly can spend as much as $90 \%$ of their time indoors (7). This observation

(Received in original form August 5, 2009; accepted in final form February 9, 2010) Supported by grants from the U.S. Environmental Protection Agency (R82672401) and the National Institute for Environmental Health Sciences grant numbers (ES09606 to P.N.B., ES03819 to J.G., and K23 ES 016819 to M.C.M.).

Correspondence and requests for reprints should be addressed to Patrick $\mathrm{N}$. Breysse, Ph.D., M.H.S., Department of Environmental Heath Sciences, Johns Hopkins University Bloomberg School of Public Health, 615 N. Wolfe Street, Baltimore, MD 21205. E-mail: pbreysse@jhsph.edu

Proc Am Thorac Soc Vol 7. pp 102-106, 2010

DOI: 10.1513/pats.200908-083RM

Internet address: www.atsjournals.org underscores the substantial contribution that indoor exposures can make to an individual's total exposure.

There are many sources of indoor air pollution in the home environment. Air pollution inside homes consists of a complex mixture of agents penetrating from ambient (outdoor) air and agents generated by indoor sources. Indoor pollutants can vary in their potential health effects and intensity, as well as in their distribution across geographic areas, cultural backgrounds, and socioeconomic status. Indoor pollutants include products of combustion, including particulate matter (PM) and oxides of nitrogen, as well as airborne allergens and endotoxin. Exposure to indoor air pollutants can cause health effects ranging from sneezing and coughing to outcomes such as cancer and exacerbation of chronic respiratory disorders such as asthma.

Asthma, a complex disease influenced by both environmental and genetic factors, is common and the prevalence is increasing worldwide (8). Childhood asthma is the most common chronic disease in children. The International Study of Asthma and Allergies in Childhood (ISAAC) estimates the asthma prevalence by country as ranging from $2 \%$ to $40 \%$ (9). Indoor environmental factors thought to modify asthma severity include pollutants such as PM, nitrogen oxides, secondhand smoke, and allergens from pests, pets, and molds (10). In contrast to the outdoor environments, people may have a greater ability to modify indoor environmental exposures. The ability to modify indoor environments makes addressing indoor air pollution an attractive target for disease prevention.

The purpose of this article is to present an overview of research on indoor pollution and asthma focusing on studies conducted by the Johns Hopkins Center for Childhood Asthma in the Urban Environment.

\section{INDOOR PARTICULATE MATTER}

Particulate matter is a principal component of indoor air pollution in homes. PM originates from a variety of humanmade and natural sources. Natural sources include pollen, spores, bacteria, plant and animal debris, and suspended crustal materials. Human-made sources consist of industrial emissions and combustion by-products from incinerators, motor vehicles, and power plants. Indoor sources include cigarette smoking, cooking, wood and other biomass burning in stoves and fireplaces, cleaning activities that re-suspend dust particles (e.g., sweeping), and penetration of outdoor particles into the indoor environment $(11,12)$. Indoor PM differs from outdoor PM in source, composition, and concentration (11, 13-16). As a result, the health effects of indoor PM cannot be readily extrapolated from studies of outdoor air pollution. Figure 1 presents the timedependent PM concentrations determined using a light scattering nephelometer (MIE pDR 1000; ThermoElectron, Franklin, MA) measured simultaneously inside a home, immediately outside the home, and at a central monitoring site. In this instance, PM 


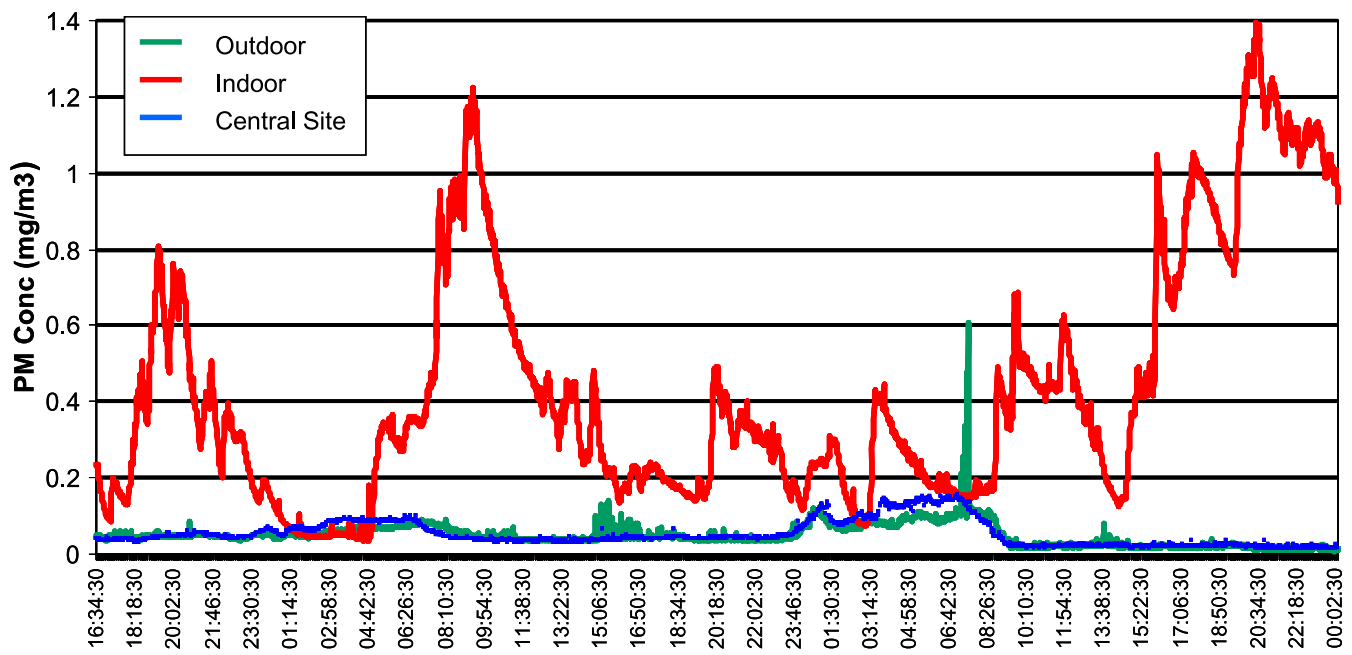

Figure 1. Comparison of particulate matter (PM) concentrations simultaneously measured indoors, immediately outdoors, and at a central monitoring site.

measured inside the home is clearly higher and more variable than outside either at the home or a central monitoring site, demonstrating the importance and complexity of addressing the health effects of indoor airborne particles.

There are relatively few studies of indoor PM and asthma. Studies of school-age children in Seattle found that indoor $\mathrm{PM}_{2.5}$ exposure was associated with decreased pulmonary function in a subgroup of 10 children not using inhaled corticosteroids (17). In this study, Koenig and coworkers (17) also found that $\mathrm{PM}_{2.5}$ originating from indoor sources was more potent in decreasing lung function than was outdoor-derived PM. A California study of 19 predominantly white children found significant decrements in lung function $\left(\mathrm{FEV}_{1}\right)$ associated with indoor PM. While this study found associations between ambient PM and lung function, they found stronger associations for indoor than outdoor central site PM concentrations (18).

A longitudinal study of 150 inner city preschool children with asthma, conducted as a part of the Johns Hopkins Center for Childhood Asthma (Baltimore Indoor Environment Study of Asthma in Kids [BIESAK] Study) investigated the impact of indoor fine $\left(\mathrm{PM}_{2.5}\right)$ and coarse PM $\left(\mathrm{PM}_{2.5-10}\right)$ on asthma morbidity (Figure 2). The mean indoor $\mathrm{PM}_{2.5}$ concentration in the BIESAK study was roughly twice as high as the indoor coarse $\mathrm{PM}$ fraction $\left(\mathrm{PM}_{2.5-10}\right)$ concentration, $40.3 \pm 35.4 \mu \mathrm{g} / \mathrm{m}^{3}$ and $17.4 \pm 21.1 \mu \mathrm{g} / \mathrm{m}^{3}$, respectively. The in-home $\mathrm{PM}_{2.5}$ and $\mathrm{PM}_{2.5-10}$ concentrations were significantly higher than the respective average ambient measurements made over the same time period, $12.4 \pm 6.2 \mu \mathrm{g} / \mathrm{m}^{3}$ and $10.3 \pm 21.0$ (Figure 2).

Significant determinants of indoor PM concentrations included smoking, sweeping, and stove use (19), activities that are modifiable and provide opportunities for exposure reduction. Smoking has been consistently described as a major source of indoor particulates over the last several decades, with more than $30 \%$ of all U.S. children exposed to secondhand smoke (20). Our results suggest that smoking continues to be a significant contributor to $\mathrm{PM}$ exposure in the inner city. The

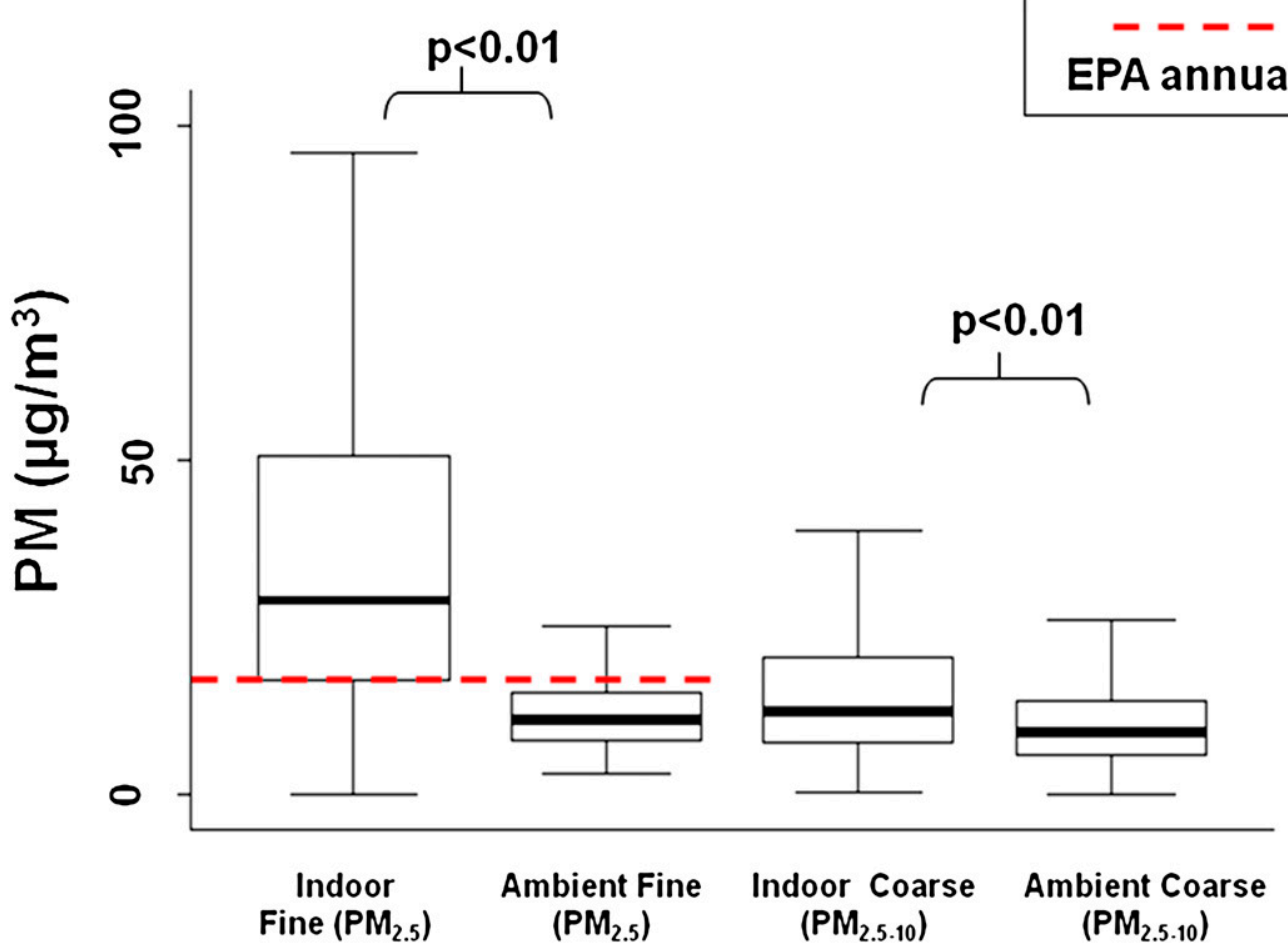

Figure 2. Distributions of indoor PM in the child's bedroom. 
difference in $\mathrm{PM}_{2.5}$ between smoking and nonsmoking households of $26 \mu \mathrm{g} / \mathrm{m}^{3}$ is similar to the range of 25 to $45 \mu \mathrm{g} / \mathrm{m}^{3}$ that has been previously reported $(11,16,21,22)$.

Indoor coarse PM concentrations were associated with substantial increases in asthma symptoms (Figure 3). For example, for every $10-\mu \mathrm{g} / \mathrm{m}^{3}$ increase in indoor $\mathrm{PM}_{2.5-10}$ concentration, there was a $6 \%$ increase in the number of days of cough, wheeze, or chest tightness, after adjusting for age, race, sex, socioeconomic status, season, indoor fine PM, and ambient fine and coarse PM concentrations. In adjusted models, higher indoor coarse PM concentration was also significantly associated with increased incidence of symptoms severe enough to slow a child's activity, wheezing that limited speaking ability, nocturnal symptoms, and rescue medication use. Outdoor coarse PM was not associated with increased asthma symptoms or rescue medication use.

Fine PM was also positively associated with respiratory symptoms and with rescue medication use (Figure 3 ). For example, for every $10-\mu \mathrm{g} / \mathrm{m}^{3}$ increase in $\mathrm{PM}_{2.5}$ measured indoors, there was a $7 \%$ increase in days of wheezing severe enough to limit speech and a $4 \%$ increase in days on which rescue medication was needed, after adjustment for potential confounders. Both indoor and ambient fine PM concentrations were also associated with exercise-related respiratory symptoms. In multivariate models adjusting for participant characteristics that were potential confounders as well as for simultaneous indoor and ambient coarse PM, for every $10-\mu \mathrm{g} / \mathrm{m}^{3}$ increase in indoor and ambient $\mathrm{PM}_{2.5}$, there was a $7 \%$ and a $26 \%$ (data on ambient PM not shown in Figure 3) increase in days of exercise-related symptoms, respectively. In contrast, neither indoor nor ambient coarse PM concentrations were associated with exercise-related symptoms.

These findings demonstrate that both indoor coarse and fine PM distinctly affect respiratory health in children with asthma. There are physiologic reasons that can explain why PM of these different size fractions can contribute separately to asthma morbidity. Although fine PM may be capable of reaching the alveoli, the regions responsible for gas exchange, the deposition of coarse PM in upper airways and subsequent bronchial

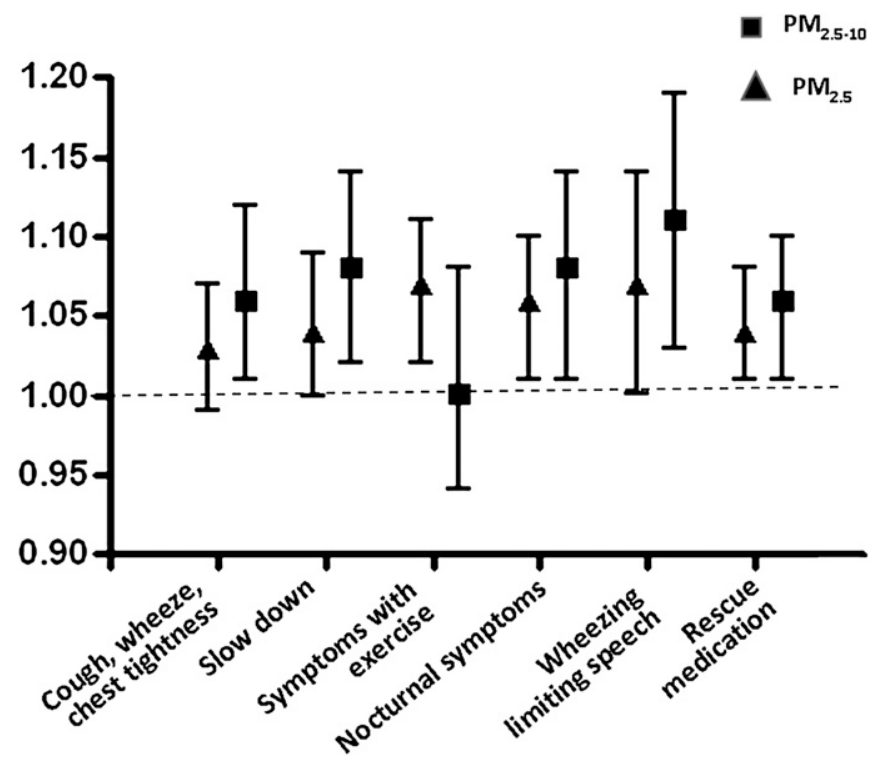

Figure 3. Indoor PM concentrations, asthma symptoms, and rescue medication use: multivariate models (coarse module adjusted for age, sex, race, parent education level, season, indoor fine PM, ambient fine PM, ambient coarse PM; fine module adjusted for age, sex, race, parent education level, season, indoor coarse PM, ambient coarse PM, ambient fine PM). hyperreactivity may be responsible for the symptomatic response measured in these preschool children.

The strong relationship between indoor and ambient fine PM exposure and exercise-related symptoms was striking in this study. Previous investigators have indicated that exercise may play a role in asthma by modifying the effect of environmental stimuli and pollutants (18). Increased exercise symptoms in response to fine PM exposure may be attributable to increased minute ventilation and an increased dose of fine PM in the distal airways and the pulmonary circulation. The increased fine PM doses in the distal airways may be more potent in eliciting exercise-related symptoms than the doses of coarse PM that deposit in the more proximal airways.

\section{INDOOR NITROGEN DIOXIDE AND ASTHMA MORBIDITY}

Nitrogen dioxide is a product of high-temperature combustion. The principal indoor source of $\mathrm{NO}_{2}$ is unvented gas appliances (stoves and furnaces). $\mathrm{NO}_{2}$ may be particularly problematic in the inner city, where gas stoves are common and proper venting rare and using stoves for heating is commonly reported. Results from the BIESAK Study have demonstrated high indoor $\mathrm{NO}_{2}$ concentrations in inner city Baltimore homes $(21,23)$.

$\mathrm{NO}_{2}$ is an irritant gas and has been linked to respiratory effects. Although some studies (24-29) have found adverse respiratory health effects from indoor $\mathrm{NO}_{2}$, other studies have failed to confirm that association (30-34). For example, data from the National Health and Nutrition Examination Survey III did not suggest any impact from gas stoves on pulmonary function or respiratory symptoms in adults with asthma (34). In contrast, the National Cooperative Inner City Asthma Study (NCICAS) conducted in eight inner cities across the United States showed a link between higher concentrations of indoor $\mathrm{NO}_{2}$ and increased symptoms and decreased peak flows in children with asthma (35).

Hansel and colleagues (36) recently reported on the effect of indoor $\mathrm{NO}_{2}$ concentrations and asthma in the BIESAK longitudinal cohort. Most of the homes in the BIESAK study were row homes (homes that share adjacent walls; $79 \%$ ) and close to the street (within $25 \mathrm{ft} ; 71 \%$ ). The overall mean ( \pm SD) indoor $\mathrm{NO}_{2}$ concentration was $30.0 \pm 33.7 \mathrm{ppb}$ (range, 2.9-394.0 ppb).

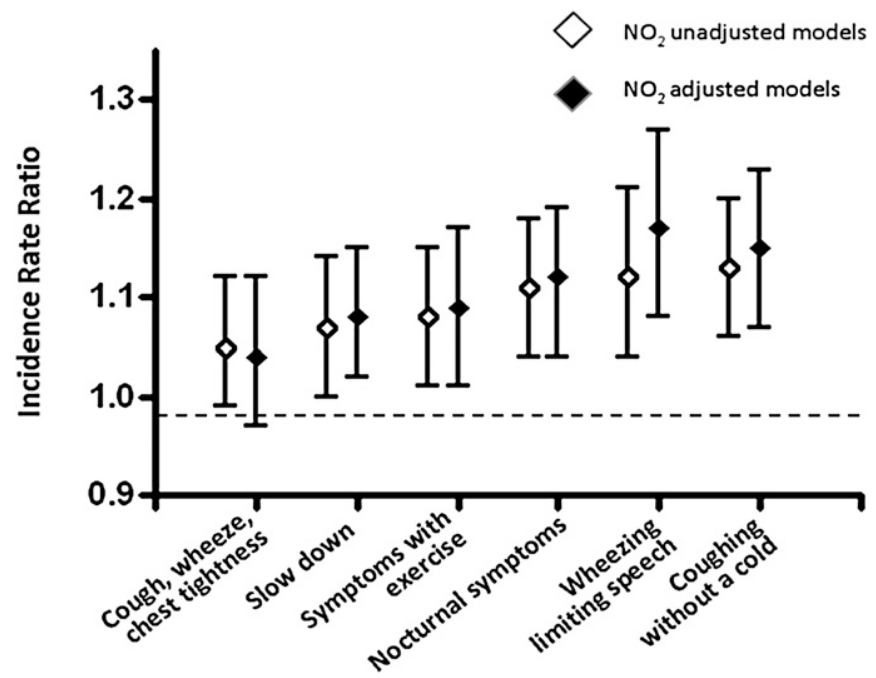

Figure 4. Risk of asthma symptoms per 20-ppb increase in $\mathrm{NO}_{2}$ exposure, adjusted for $\mathrm{PM}_{2.5}$; second hand smoke; distance from the curb; type of street in front of house; season of sampling; age, sex, and race of child; and mother's education level. 


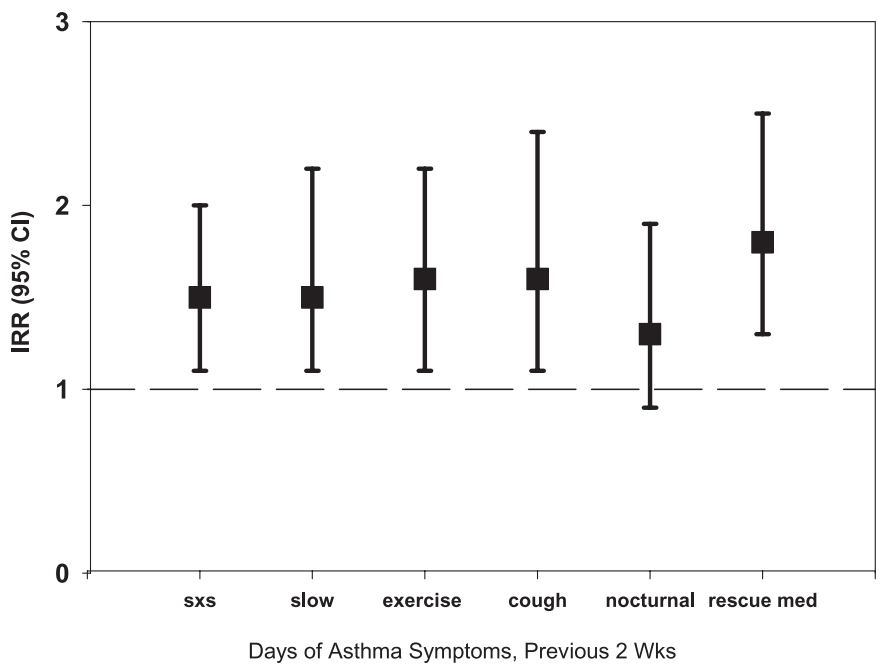

Figure 5. Recent asthma symptoms and rescue medication use among mouse-sensitized, highly exposed children. Adjusted for age, sex, atopy, cockroach sensitization and exposure, public health insurance, and study visit.

$\mathrm{NO}_{2}$ concentrations were significantly lower in summer $(15.9 \pm$ $14.0 \mathrm{ppb})$ than in any other season. The mean ambient $\mathrm{NO}_{2}$ concentration during the study period was $25.7 \mathrm{ppb}$, and there was minimal correlation $\left(r^{2}=0.056, P<0.01\right)$ between ambient and indoor $\mathrm{NO}_{2}$ concentrations. $\mathrm{NO}_{2}$ concentrations were higher in homes with a gas stove (mean, $33.1 \mathrm{ppb}$ ) compared with those without a gas stove (mean, $16.8 \mathrm{ppb}$ ). Similarly, the mean indoor $\mathrm{NO}_{2}$ concentrations were $7.2 \mathrm{ppb}$ higher in homes with a gas heater compared with those without a gas heater, and the presence of a gas heater had a greater effect on indoor $\mathrm{NO}_{2}$ concentrations during the winter months.

As summarized in Figure 4, higher $\mathrm{NO}_{2}$ concentrations were associated with statistically significant increases in respiratory symptoms in preschool children with asthma. After adjusting for potential confounders, increasing $\mathrm{NO}_{2}$ concentrations were significantly associated with increasing frequency of limited speech due to wheezing, coughing without a cold, and nocturnal awakenings due to cough, wheeze, and shortness of breath or chest tightness during the daytime and while running. There was no significant relationship between $\mathrm{NO}_{2}$ concentration and rescue medication use in the previous two weeks or health care utilization. In general, the presence of atopy did not modify the effect of $\mathrm{NO}_{2}$ exposure on asthma symptoms, except that individuals with atopy were more likely to experience nocturnal symptoms with increasing $\mathrm{NO}_{2}$ concentration (Incidence Rate Ratio [IRR] $=1.13$ per 20-ppb increase in $\mathrm{NO}_{2}$ ) compared with nonatopic individuals $($ IRR $=1.03)$. In addition, daily use of inhaled corticosteroids (ICS) did not modify the association of $\mathrm{NO}_{2}$ concentrations and asthma symptoms, and mean ambient $\mathrm{NO}_{2}$ concentrations were not significantly associated with any respiratory symptoms.

\section{MOUSE ALLERGEN AND ASTHMA}

Asthma is an allergic and inflammatory disease, and exposure to indoor allergens is a widely recognized risk factor for asthma morbidity (37). Allergens can be produced from pests (mites, cockroaches, rodents), pets (cats, dogs), plants (pollen), and fungi (mold spores). Allergens as risk factors for asthma have been widely studied $(38,39)$. Mouse allergen, a well-recognized occupational allergen, has only recently been identified as a common household allergen. Matsui and coworkers investigated the role of mouse allergen exposure in the BIESAK cohort and other homes

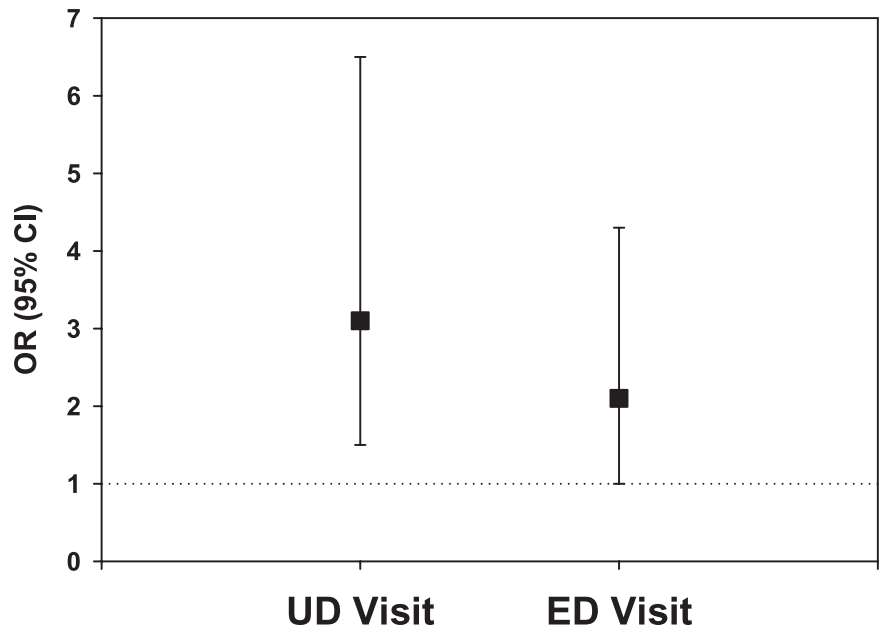

Figure 6. Asthma health care use among mouse-sensitized, highly exposed children adjusted for age, sex, atopy, cockroach sensitization and exposure, public health insurance, and study visit.

in Baltimore, MD $(39,40)$, reporting that $100 \%$ of homes in inner city Baltimore had detectable mouse allergen in settled dust samples. In addition, airborne mouse allergen was detected in greater than $80 \%$ of the bedrooms sampled. Settled dust concentrations of mouse allergen that exceeded $0.5 \mu \mathrm{g} / \mathrm{g}$ were found to be predictive of having detectable airborne mouse allergen (39).

In the BIESAK cohort, both asthma symptoms and asthmarelated health care use were more common among mousesensitized participants who had greater than $0.5 \mu \mathrm{g} / \mathrm{g}$ of mouse allergen in their bedroom dust sample than in the others (Figures 5 and 6). The associations between mouse allergen exposure and asthma outcomes were found to be independent of cockroach sensitization/exposure, public health insurance, atopy, age, and sex.

\section{CONCLUSIONS}

Analyses of exposure outcome relationships in the BIESAK cohort and other studies mentioned in this review demonstrate the importance of evaluating indoor home air pollution sources as risk factors for asthma morbidity. Results presented indicate that indoor particulate matter (particularly the coarse fraction), $\mathrm{NO}_{2}$, and mouse allergen exposure are important determinants of asthma morbidity in urban environments.

Avoidance of harmful exposures is a key component of national and international guideline recommendations for management of asthma $(41,42)$. Guidelines identify $\mathrm{PM}$ and $\mathrm{NO}_{2}$ as pollutants of concern, but specific recommendations are limited and focused mostly on avoiding exposure to elevated outdoor concentrations. Objective measure of indoor air exposures may be indicated for children with uncontrolled asthma. These results from the BIESAK and other studies suggest that modifying the indoor environment to reduce $\mathrm{PM}, \mathrm{NO}_{2}$, and mouse allergen may be an important asthma management strategy. More research documenting effectiveness of interventions to reduce those exposures and improve asthma outcomes is needed.

Conflict of Interest Statement: P.N.B. does not have a financial relationship with a commercial entity that has an interest in the subject of this manuscript. G.B.D. served as a consultant for Merck \& Co., Inc, GlaxoSmithKline $(\$ 1,001-\$ 5,000)$, and Healthways $(\$ 10,001-\$ 50,000)$. He served on the Board or Advisory Board for Merck \& Co, Inc. $(\$ 1,001-\$ 5,000)$ and received lecture fees from AstraZeneca, Pfizer $(\$ 10,001-\$ 50,000)$, Boehinringer Ingelheim $(\$ 1,001-\$ 5,000)$, and Schering Plough $(\$ 5,001-\$ 10,000)$. He served as an expert witness for Firminich $(\$ 50,001-\$ 100,000)$ and received grant support from Hill-Rom, Inc. (former Adanced Respiratory) (\$10,001-\$50,000), Eumdedic $(\$ 50,001-\$ 100,000)$, 
Asthmatix (\$100,001 or more), Novartis (up to $\$ 1,000)$, the National Institutes of health $(\mathrm{NIH})$, the Environmental Protection Agency, and Housing and Urban Development (\$100,001 or more). His institution served as a consultant for Healthways (\$100,001 or more). E.C.M. received grant support from the NIH $(\$ 100,001$ or more). A.M.B. does not have a financial relationship with a commercial entity that has an interest in the subject of this manuscript. N.N.H. served as a consultant for Pfizer $(\$ 1,001-\$ 5,000)$ and received grant support from Pfizer and the NIH (\$100,001 or more). M.C.M. received lecture fees from Pfizer (Up to $\$ 1,000)$. Her spouse received grant support from Gilead Sciences Research Scholars Program $(\$ 50,001-\$ 100,000)$. She has received grant support from the National Institute for Environmental Health Sciences and the NIH ( $\$ 100,001$ or more).

\section{References}

1. Pruss-Ustun A, Corvalan C. Preventing disease through healthy environments: towards an estimate of the environmental burden of disease. Geneva, Switzerland: World Health Organization; 2006.

2. Pope CA III, Dockery DW. Health effects of fine particulate air pollution: lines that connect. J Air Waste Manag Assoc 2006;56:709-742.

3. Committee on Environmental Health. Ambient air pollution: health hazards to children. Pediatrics 2004;114:1699-1707.

4. Pope CA III, Ezzati M, Dockery DW. Fine-particulate air pollution and life expectancy in the United States. N Engl J Med 2009;360:376-386.

5. Samet J, Krewski D. Health effects associated with exposure to ambient air pollution. J Toxicol Environ Health A 2007;70:227-242.

6. Dockery DW, Stone PH. Cardiovascular risks from fine particulate air pollution. N Engl J Med 2007;356:511-513.

7. Klepeis NE, Nelson WC, Ott WR, Robinson JP, Tsang AM, Switzer P, Behar JV, Hern SC, Engelmann WH. The National Human Activity Pattern Survey (NHAPS): a resource for assessing exposure to environmental pollutants. J Expo Anal Environ Epidemiol 2001;11:231-252.

8. Holgate ST. The epidemic of allergy and asthma. Nature 1999;402:B2-B4.

9. The International Study of Asthma and Allergies in Childhood (ISAAC). Worldwide variation in prevalence of symptoms of asthma, allergic rhinoconjunctivitis, and atopic eczema: ISAAC. The International Study of Asthma and Allergies in Childhood (ISAAC) Steering Committee. Lancet 1998;351:1225-1232.

10. Diette GB, McCormack MC, Hansel NN, Breysse PN, Matsui EC. Environmental issues in managing asthma. Respir Care 2008;53:602615, discussion 616-617.

11. Wallace LA, Mitchell H, O’Connor GT, Neas L, Lippmann M, Kattan M, Koenig J, Stout JW, Vaughn BJ, Wallace D, et al. Inner-City Asthma Study. Particle concentrations in inner-city homes of children with asthma: the effect of smoking, cooking, and outdoor pollution. Environ Health Perspect 2003;111:1265-1272.

12. McCormack MC, Breysse PN, Hansel NN, Matsui EC, Tonorezos ES, Curtin-Brosnan J, Williams DL, Buckley TJ, Eggleston PA, Diette GB. Common household activities are associated with elevated particulate matter concentrations in bedrooms of inner-city Baltimore pre-school children. Environ Res 2008;106:148-155.

13. Allen R, Larson T, Sheppard L, Wallace L, Liu LJ. Use of real-time light scattering data to estimate the contribution of infiltrated and indoorgenerated particles to indoor air. Environ Sci Technol 2003;37:3484-3492.

14. Long CM, Suh HH, Koutrakis P. Characterization of indoor particle sources using continuous mass and size monitors. J Air Waste Manag Assoc 2000;50:1236-1250.

15. Turpin BJ, Weisel CP, Morandi M, Colome S, Stock T, Eisenreich S, Buckley B. Relationships of Indoor, Outdoor, and Personal Air (RIOPA): part II. Analyses of concentrations of particulate matter species. Res Rep Health Eff Inst 2007; (130 Pt 2):1-77, discussion 79-92.

16. Wallace L. Indoor particle: a review. J Air Waste Manag Assoc 1996;46: 98-126.

17. Koenig JQ, Mar TF, Allen RW, Jansen K, Lumley T, Sullivan JH, Trenga CA, Larson T, Liu LJ. Pulmonary effects of indoor- and outdoor-generated particles in children with asthma. Environ Health Perspect 2005;113:499-503.

18. McConnell R, Berhane K, Gilliland F, Molitor J, Thomas D, Lurmann F, Avol E, Gauderman WJ, Peters JM. Prospective study of air pollution and bronchitic symptoms in children with asthma. Am J Respir Crit Care Med 2003;168:790-797.

19. McCormack MC, Breysse PN, Hansel NN, Matsui EC, Tonorezos ES, Curtin-Brosnan J, Williams DL, Buckley TJ, Eggleston PA, Diette GB. Common household activities are associated with elevated particulate matter concentrations in bedrooms of inner-city Baltimore pre-school children. Environ Res 2008;106:148-155.

20. Winickoff JP, Berkowitz AB, Brooks K, Tanski SE, Geller A, Thomson C, Lando HA, Curry S, Muramoto M, Prokhorov AV, et al., Tobacco
Consortium, Center for Child Health Research of the American Academy of Pediatrics. State-of-the-art interventions for office-based parental tobacco control. Pediatrics 2005;115:750-760.

21. Breysse PN, Buckley TJ, Williams D, Beck CM, Jo SJ, Merriman B, Kanchanaraksa S, Swartz LJ, Callahan KA, Butz AM, et al. Indoor exposures to air pollutants and allergens in the homes of asthmatic children in inner-city Baltimore. Environ Res 2005;98:167-176.

22. Ozkaynak H, Xue J, Spengler J, Wallace L, Pellizzari E, Jenkins P. Personal exposure to airborne particles and metals: results from the Particle TEAM study in Riverside, California. J Expo Anal Environ Epidemiol 1996;6:57-78.

23. Diette GB, Hansel NN, Buckley TJ, Curtin-Brosnan J, Eggleston PA, Matsui EC, McCormack MC, Williams DL, Breysse PN. Home indoor pollutant exposures among inner-city children with and without asthma. Environ Health Perspect 2007;115:1665-1669.

24. Garrett MH, Hooper MA, Hooper BM, Abramson MJ. Respiratory symptoms in children and indoor exposure to nitrogen dioxide and gas stoves. Am J Respir Crit Care Med 1998;158:891-895.

25. Hasselblad V, Eddy DM, Kotchmar DJ. Synthesis of environmental evidence: nitrogen dioxide epidemiology studies. J Air Waste Manage Assoc 1992;42:662-671.

26. Shima M, Adachi M. Effect of outdoor and indoor nitrogen dioxide on respiratory symptoms in schoolchildren. Int J Epidemiol 2000;29:862-870.

27. Belanger K, Gent JF, Triche EW, Bracken MB, Leaderer BP. Association of indoor nitrogen dioxide exposure with respiratory symptoms in children with asthma. Am J Respir Crit Care Med 2006;173:297-303.

28. Nitschke M, Pilotto LS, Attewell RG, Smith BJ, Pisaniello D, Martin J, Ruffin RE, Hiller JE. A cohort study of indoor nitrogen dioxide and house dust mite exposure in asthmatic children. J Occup Environ Med 2006;48:462-469.

29. Smith BJ, Nitschke M, Pilotto LS, Ruffin RE, Pisaniello DL, Willson KJ. Health effects of daily indoor nitrogen dioxide exposure in people with asthma. Eur Respir J 2000;16:879-885.

30. Florey CV, Melia RJ, Chinn S, Goldstein BD, Brooks AG, John HH, Craighead IB, Webster X. The relation between respiratory illness in primary schoolchildren and the use of gas for cooking-III. Nitrogen dioxide, respiratory illness and lung infection. Int J Epidemiol 1979;8: 347-353.

31. Hoek G, Brunekreef B, Meijer R, Scholten A, Boleij J. Indoor nitrogen dioxide pollution and respiratory symptoms of schoolchildren. Int Arch Occup Environ Health 1984;55:79-86.

32. Samet JM, Lambert WE, Skipper BJ, Cushing AH, Hunt WC, Young SA, McLaren LC, Schwab M, Spengler JD. Nitrogen dioxide and respiratory illnesses in infants. Am Rev Respir Dis 1993;148:1258-1265.

33. Sunyer J, Puig C, Torrent M, Garcia-Algar O, Calico I, Munoz-Ortiz L, Barnes M, Cullinan P, Asthma Multicentre Infants Cohort Study. Nitrogen dioxide is not associated with respiratory infection during the first year of life. Int J Epidemiol 2004;33:116-120.

34. Eisner MD, Blanc PD. Gas stove use and respiratory health among adults with asthma in NHANES III. Occup Environ Med 2003;60:759-764.

35. Kattan M, Gergen PJ, Eggleston P, Visness CM, Mitchell HE. Health effects of indoor nitrogen dioxide and passive smoking on urban asthmatic children. J Allergy Clin Immunol 2007;120:618-624.

36. Hansel NN, Breysse PN, McCormack MC, Matsui EC, Curtin-Brosnan J, Williams DL, Moore JL, Cuhran JL, Diette GB. A longitudinal study of indoor nitrogen dioxide levels and respiratory symptoms in innercity children with asthma. Environ Health Perspect 2008;116:1428-1432.

37. Institute of Medicine. Committee on the assessment of asthma and indoor air. Washington, D.C.: National Academy Press; 2000.

38. Matsui EC, Hansel NN, McCormack MC, Rusher R, Breysse PN, Diette GB. Asthma in the inner city and the indoor environment. Immunol Allergy Clin North Am 2008;28:665-686.

39. Matsui EC, Simons E, Rand C, Butz A, Buckley TJ, Breysse P, Eggleston PA. Airborne mouse allergen in the homes of inner-city children with asthma. J Allergy Clin Immunol 2005;115:358-363.

40. Matsui EC, Eggleston PA, Buckley TJ, Krishnan JA, Breysse PN, Rand CS, Diette GB. Household mouse allergen exposure and asthma morbidity in inner-city preschool children. Ann Allergy Asthma Immunol 2006;97:514-520.

41. National Heart, Lung, and Blood Institute, National Asthma Education and Prevention Program. Expert Panel Report 3: Guidelines for the Diagnosis and Management of Asthma.: National Institutes of Health, US Department of Health and Human Services; Full Report 2007. NIH Publication No. 07-4051.

42. Global Initiative for Asthma. GINA Workshop Report: Global Strategy for Asthma Management and Prevention.; 2006. 